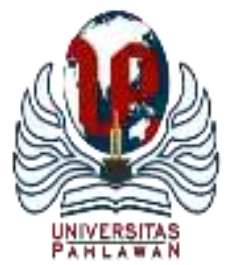

Edukatif : Jurnal Ilmu Pendidikan Volume 3 Nomor 6 Tahun 2021 Halm 5092 - 5100

EDUKATIF: JURNAL ILMU PENDIDIKAN

Research \& Learning in Education

https://edukatif.org/index.php/edukatif/index

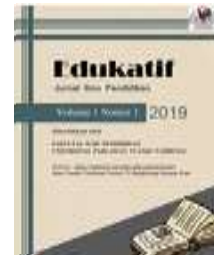

\title{
Blended Learning dan Implikasinya terhadap Hasil Belajar Geografi Siswa SMA di Era Pandemi Covid-19
}

\author{
Lesmiyati Hariyani ${ }^{凶}$ \\ SMAN Darussholah Singojuruh, Indonesia \\ E-mail : hariyaniles@gmail.com
}

\begin{abstract}
Abstrak
Pandemi Covid-19 yang semakin meningkatkan, sistem pembalajaran onine dapat mempermudah siswa, guru dan kelancaran pembelajaraan. Tujuan dalam penelitian ini yaitu untuk mengetahui implikasi Blend Learning dalam hasil belajar mata pelajaran Geografi pada era Pandemi Covid-19. Penelitian ini menggunakan penelitian kepustakaan, dimana pengumpulan datanya berasal berbagai jurnal maupun buku yang dianalisis sesuai dengan masalah yang ada. Hasil dalam penelitian ini yaitu terdapat beberapa problematika dari beberapa pihak, yaitu guru, siswa hingga orang tua siswa. Guru dituntut dapat bisa beradaptasi dengan model pembelajaran bermodel blended learning pada masa pandemi saat ini. Perubahan lingkungan belajar akan mempengaruhi masalah psikologis siswa. Permasalahan yang dihadapi siswa berupa stigma bahwa kegiatan belajar (sekolah) harus berlangsung di lembaga pendidikan, jika di rumah berarti sedang berlibur. Tidak semua orang tua memiliki keterampilan menggunakan IT dan perangkat kerja berbasis internet, hal ini juga menjadi tantangan dan membutuhkan waktu untuk beradaptasi. Hal tersebut dapat diatasi oleh pelaksanaan pembelajaran dapat dirancang melalui kombinasi media pembelajaran, karena gaya belajar setiap siswa berbeda. Kita sebagai pendidik atau orang tua tidak dapat memaksa siswa untuk belajar dalam suasana dan cara yang kita inginkan, karena setiap siswa atau individu memiliki tipe atau gaya belajarnya masing-masing.
\end{abstract}

Kata Kunci: Blended Learning, Geografi, Pandemi Covid-19

\begin{abstract}
The Covid-19 pandemic is increasing, the online learning system can make it easier for students, teachers, and smooth learning. The purpose of this study is to find out the implications of Blend Learning in the learning outcomes of Geography subjects in the Covid-19 Pandemic era. This study uses library research, where the data collection comes from various journals and books which are analyzed according to the existing problems. The results in this study show that there are several problems from several parties, namely teachers, students to parents of students. Teachers are required to be able to adapt to the blended learning model during the current pandemic. Changes in the learning environment will affect students' psychological problems. The problem faced by students is the stigma that learning activities (school) must take place in educational institutions if at home means being on vacation. Not all parents have the skills to use IT and internet-based work tools, this is also a challenge and takes time to adapt. This can be overcome by the implementation of learning can be designed through a combination of learning media, because each student's learning style is different. We as educators or parents cannot force students to learn in the atmosphere and way we want, because every student or individual has a different type of learning style.
\end{abstract}

Keywords: Blended Learning, Geography, Covid-19 Pandemic

Copyright (c) 2021 Lesmiyati Hariyani

$\triangle$ Corresponding author:

Email : hariyaniles@gmail.com $\quad$ ISSN 2656-8063 (Media Cetak)

DOI : https://doi.org/10.31004/edukatif.v3i6.1643

ISSN 2656-8071 (Media Online)

Edukatif : Jurnal Ilmu Pendidikan Vol 3 No 6 Tahun 2021 p-ISSN 2656-8063 e-ISSN 2656-8071 
5093 Blended Learning dan Implikasinya terhadap Hasil Belajar Geografi Siswa SMA di Era Pandemi Covid-19 - Lesmiyati Hariyani

DOI: https://doi.org/10.31004/edukatif.v3i6.1643

\section{PENDAHULUAN}

Di Indonesia Covid-19 muncul sebagai wabah nasional pada tanggal 11 Maret 2020, yang mempengaruhi berbagai sektor, mulai dari sektor ekonomi, transportasi hingga pendidikan. Dalam sektor pendidikan, saat ini sektor tersebut melakukan penyeseuaian antara lain melalui pembelajaran daring (Yudiawan, 2020). Pembelajaran online adalah pembelajaran dengan media Selama ini proses belajar mengajar dilaksanakan dengan cara konvensional di kelas tatap muka (offline), sejak pendidikan ke-9 tidak lagi berlangsung di dalam kelas, melainkan di layar laptop, komputer dan smartphone. Dikenal dengan istilah pembelajaran jarak jauh, pembelajaran online dan pembelajaran online. Pandemi Covid-19 sebagian besar telah berhasil dalam revolusi teknologi dan transformasi sistem pendidikan global, khususnya di Indonesia, tanpa harus dilaksanakan secara tatap muka, sehingga menggunakan jaringan internet (Masykuri, 2020).

Hal yang paling nyata sebagai dampak pandemi di dunia pendidikan ini yakni kebingungan para pendidik dalam menerapkan kegiatan belajar mengajar di tengah-tengah keterbatasan gerak dan sarana. Kebijakan pemerintah untuk mengurangi penyebaran covid-19 ini salah satunya meniadakan Ujian Nasional (UN) tahun 2020 dan tatap muka dalam kegiatan pembelajaran dengan mengeluarkan Surat Edaran Nomor 4 Tahun 2020 tentang Pelaksanaan Pendidikan Dalam Masa Darurat Coronavirus Disease (Covid-19). Seluruh masyarakat dianjurkan kerja dari rumah, belajar dari rumah dan beribadah di rumah. Maka dari itu, kegiatan pembelajaran dilakukan secara online atau dalam jaringan (daring). Para pendidik mulai membuka kembali berbagai metode alternatif yang bisa digunakan dalam masa-masa daring ini. Tentu hal ini tidaklah mudah, mengingat proses ini dilakukan dalam waktu cepat dan harus dilakukan.

Metode pembelajaran merupakan implementasi dari rencana yang ada pada strategi pembelajaran. Maka dengan metode yang dipilih dalam pembelajaran diharapkan bisa mencapai tujuan pembelajaran seefesien dan seefektif mungkin. Dalam tatap muka, metode-metode lebih mudah dilaksanakan dalam proses pembelajaran. Ruang, waktu serta kebersamaan siswa dan guru bisa ada dalam satu waktu kegiatan belajar mengajar. Siswa akan lebih mudah bertanya, mengemukakan pendapat, berinteraksi dengan nyata serta memperoleh role model yang bisa memberi makna dan nilai-nilai pendidikan. Dalam kondisi masa sebaran Covid-19, sistem pembelajaran online dapat digunakan untuk keselamatan siswa, guru, dan kelancaran pembelajaran (Jamaluddin, Ratnasih, Gunawan, \& Paujiah, 2020). Salah satu model pembelajaran online yang paling efektif di era pandemi adalah blended learning. Blended learning menggabungkan pengajaran di kelas dengan pembelajaran online (Utari, Hikmawati, \& Gaffar, 2020).

Penerapan blended learning di masa pandemi merupakan sarana optimalisasi pembelajaran online di masa pandemi agar proses pembelajaran di masa pandemi efektif dan efisien (Purnama, 2020). Nurhadi (2020) mengatakan blended learning dan implikasinya di era pandemi dapat menghemat biaya. Selain itu, dijelaskan oleh Dihamri et al. (2021) bahwa blended learning dapat meningkatkan motivasi belajar dan pemahaman guru dan siswa di bidang teknologi. Dengan demikian, blended learning menjadi solusi model pembelajaran di era pandemi Covid 19.

Untuk mengembangkan model blended learning, guru perlu menganalisis tren pembelajaran saat ini, terutama yang terkait dengan strategi dan konten pembelajaran (Dwiyogo, 2018). Ada kecenderungan strategi pengajaran untuk beralih dari metode pengajaran tradisional ke pengajaran modern, yang disebut sebagai Age of Knowledge, dimana siswa dapat belajar dimana saja, kapan saja, dengan siapa saja, artinya tersedia berbagai sumber belajar bagi siswa berdiri, yaitu guru, ahli, praktisi atau masyarakat dengan berbagai cara. Selain itu, siswa juga dapat memanfaatkan media pembelajaran seperti internet, radio, televisi, laboratorium atau pengalamannya sendiri (Medina, 2017).

Hasil penelitian Dwiyogo (2018) menunjukkan bahwa kontribusi komponen blended learning menjelaskan bahwa komponen pembelajaran yang memberikan kontribusi paling besar terhadap blended learning adalah tugas, buku teks, presentasi tatap muka, dan kuliah tatap muka dengan guru. Video 
5094 Blended Learning dan Implikasinya terhadap Hasil Belajar Geografi Siswa SMA di Era Pandemi Covid-19 - Lesmiyati Hariyani

DOI: https://doi.org/10.31004/edukatif.v3i6.1643

pembelajaran online juga berkontribusi pada pembelajaran, sementara buku teks online memberikan kontribusi rata-rata untuk pembelajaran. Meskipun kontribusi mereka dalam pembelajaran relatif kecil, siswa berpikir bahwa mereka kadang-kadang menggunakan video dan buku teks online untuk belajar.

Tantangan dan permasalahan yang muncul dalam proses implementasi online sangat kompleks, mulai dari guru, siswa, lembaga pendidikan dan juga orang tua siswa. Tantangan tersebut salah satunya yaitu kurangnya teknologi atau tidak menguasainya dengan baik, mencari dan menyiapkan berbagai metode atau materi yang disediakan sehingga tidak membosankan namun dapat menciptakan pembelajaran yang inovatif untuk digunakan siswa (Utari et al., 2018). Masalah kuota internet muncul kepada setiap siswa, yang dengan adanya online berarti banyak kuota yang digunakan. Bahkan di daerah yang jauh dari metropolitan yang tidak memiliki akses internet, siswa masih harus berjalan beberapa kilometer untuk mengakses internet (Kusnayat et al., 2020)

Dengan demikian, ketika melaksanakan pembelajaran di era pandemi, dukungan teknologi dapat digunakan dalam perancangan dan perencanaan proses pembelajaran, pelaksanaan dan evaluasi proses pembelajaran, namun dengan banyak masalah dalam penerapan teknologi pembelajaran dan pembelajaran. Agar tidak menimbulkan masalah baru, diperlukan kombinasi dalam proses pembelajaran, karena banyak kendala khususnya keterbatasan jaringan yang tentunya menyebabkan proses pembelajaran menjadi tidak efektif yaitu blended learning harus diimplementasikan dalam proses pembelajaran agar pembelajaran online berjalan efektif.

\section{METODE PENELITIAN}

Penelitian ini betujuan menganalisis pemebelajaran daring yang terjadi selama masa pandemi, meliputi media yang banyak digunakan dalam proses pembelajaran, ciri pembelajaran daring berikut kelebihan dan kendala yang dihadapi dalam pelaksanaannya. Adapun metode yang digunakan ialah kajian literatur yang dikenal juga dengan. Kajian literatur ini merujuk pada kajian teoritis dan referensi lain yang berhubungan dengan nilai, sosial budaya dan norma yang berkembang pada situasi sosial yang diteliti. Karena itu penelitian jenis ini akan mengumpulkan dan mengkaji dari literatur-literatur ilmiah (Sugiyono, 2017:23)

Setelah ditentukan topik terkait penelitian, penulis mengumpulkan data yang sesuai untuk dikaji dalam penelitian ini baik berupa jurnal penelitian nasional maupun internasional, kebijakan pemerintah terkait pembelajaran di rumah pada masa pandemi, artikel, surat kabar serta literartur lainnya yang menunjang. Oleh karena itu, teknis analisis data yang digunakan yakni secara kualitatif dengan model Miles and Huberman (Sugiyono, 2017:45) yaitu melalui empat tahapan analisis. Pertama data collecting (pengumpulan data) yakni mencari data berupa literatur baik jurnal penelitian, peraturan pemerintah tentang proses pembelajaran masa pandemi, artikel dan surat kabar. Kedua data reduction (reduksi data) yakni merangkum, memilih hal-hal yang pokok dan penting dari data yang diperoleh. Tahap ketiga data display (penyajian data) yaitu dalam library research ini bentuk penyajian data dibuat dengan membuat uraian dalam teks yang bersifat naratif. Terakhir tahap keempat adalah conclusion drawing/verification (penarikan kesimpulan dan verifikasi) yaitu setelah memilih data-data penting dari literatur terkait topik yang diteliti dan menarasikan dalam bentuk deskriptif, maka berikutnya adalah mengambil kesimpulan. Di tahap ini akan tergambar rumusan masalah atau temuan dari penelitian tentang analisis pembelajaran daring selama pandemi.

\section{HASIL DAN PEMBAHASAN PENELITIAN}

\section{Konsep Blended Learning}

Istilah blended learning secara gramatikal terdiri dari dua kata, yaitu blended dan learning. Kata "blend" artinya campuran untuk meningkatkan kualitas menjadi lebih baik atau rumusan kombinasi atau perpaduan yang serasi (Kutsiyyah, 2021). Sedangkan "learning” mempunyai arti umum yaitu belajar, secara 
5095 Blended Learning dan Implikasinya terhadap Hasil Belajar Geografi Siswa SMA di Era Pandemi Covid-19 - Lesmiyati Hariyani

DOI: https://doi.org/10.31004/edukatif.v3i6.1643

sepintas meliputi pengertian pola belajar yang berunsur percampuran atau kombinasi antara pola yang satu dengan yang lainnya.

Dziuban \& Moskal (2011) menunjukkan bahwa blended learning dapat meningkatkan hasil belajar siswa dan tingkat sekolah yang lebih rendah dibandingkan dengan pembelajaran online penuh. Kami juga menemukan bahwa model pembelajaran berbasis campuran lebih unggul daripada pembelajaran tatap muka. Belajar pada hakekatnya adalah suatu proses perubahan tingkah laku (kognisi, emosi, psikomotor) dan relatif permanen untuk latihan dan pengalaman (Dihamri et al., 2021). Siswa dan guru/fasilitator bekerja sama untuk meningkatkan kualitas pembelajaran. Tujuan blended learning yaitu untuk menciptakan peluang bagi karakteristik peserta didik yang berbeda sehingga terjadi pembelajaran yang mandiri, berkelanjutan dan sepanjang hayat sehingga pembelajaran menjadi lebih efektif dan efisien.

Blended learning terbagi menjadi tiga jenis pembelajaran yaitu, pembelajaran di kelas, offline dan online. Pembelajaran pribadi sebagai salah satu bentuk model pembelajaran tradisional yang mempertemukan guru (guru atau dosen) dengan siswa dalam satu ruang pengajaran yang sama. Pengajaran tatap muka adalah serangkaian kegiatan yang dirancang untuk mendukung belajar siswa secara langsung. Model pembelajaran tatap muka menekankan pada pengenalan dan demonstrasi pembelajaran serta menuntut peserta untuk terus bertemu dan berinteraksi setiap minggunya dalam konteks pembelajaran (Ceylan \& Kesici, 2017). Pembelajaran tatap muka lebih menitikberatkan pada kegiatan siswa. Pembelajaran tatap muka memungkinkan guru mengetahui keterbatasan siswa. Pembelajaran offline sering disamakan dengan pembelajaran menggunakan media berbasis komputer tanpa jaringan internet. Salah satu model pembelajaran offline adalah penggunaan multimedia. Abroto et al. (2021) mengemukakan bahwa perubahan proses belajar mengajar melalui pengenalan teknologi multimedia dalam pendidikan tidak dapat dihindari. Nurhadi (2020) menyarankan agar mahasiswa mencari banyak cara untuk menimba ilmu, termasuk memaksimalkan komputer.

Menurut Dwiyogo (2018) komponen multimedia adalah: (1) harus ada komputer yang mengoordinasikan apa yang kita lihat dan dengar dan yang berinteraksi dengan kita, (2) harus ada koneksi yang menghubungkan kita dengan 3) kita menjelajah jaringan informasi jaringan, (4) Multimedia menawarkan tempat di mana kita dapat mengumpulkan, memproses dan mengirimkan informasi dan ide kita sendiri (Susanti \& Prameswari, 2020).

Pembelajaran online merupakan hasil pengajaran yang diajarkan secara elektronik dengan menggunakan media komputerisasi dan sering diakses melalui jaringan internet yang membantu siswa mencapai hasil tertentu (Utari et al., 2020). Dalam pembelajaran online, proses belajar mengajar tetap lebih fleksibel dari segi waktu dan lokasi (Nande \& Irman, 2021). Kegiatan belajar mengajar yang dilakukan secara online yang dipadukan dengan acara tatap muka berdampak pada nilai akhir siswa (Dziuban \& Moskal, 2011). Nurhadi (2020) menjelaskan empat hal yang berimplikasi pada pembelajaran online, yaitu: (1) Siswa harus secara tegas menentukan apa yang akan dihasilkan sehingga dapat memutuskan pilihan studi apa yang dimilikinya, (2) Siswa harus mampu mandiri. menilai berhasil atau tidaknya pembelajaran online, (3) bahan ajar harus memiliki tahapan-tahapan yang sesuai untuk menunjang pembelajaran, tahapan dari yang sederhana ke kompleks, mudah dan sulit, (4) siswa harus terbiasa dilengkapi dengan umpan balik sehingga dapat memantau kinerja mereka dan memperbaiki kesalahannya.

Menurut Masgumelar \& Mustafa (2021) terdapat kelebihan dan kekurangan dalam implikasi blended learning, yaitu: Kelebihan blended learning: (a) Pembelajaran berlangsung secara mandiri dan konvensional, dimana keduanya memiliki kelebihan yang dapat saling melengkapi, (b) Pembelajaran lebih efektif dan efisien, (c) aksesibilitas yang lebih baik. Blended learning memudahkan peserta didik untuk mengakses materi pembelajaran.

Kekurangan blended learning: (a) Media yang dibutuhkan sangat beragam, sehingga sulit dalam pelaksanaannya jika sarana dan prasarana tidak mendukung, (b) fasilitas peserta didik tidak merata, seperti 
5096 Blended Learning dan Implikasinya terhadap Hasil Belajar Geografi Siswa SMA di Era Pandemi Covid-19 - Lesmiyati Hariyani

DOI: https://doi.org/10.31004/edukatif.v3i6.1643

komputer dan akses internet. Sementara akses internet yang memadai diperlukan dalam blended learning, jaringan yang tidak memadai menyulitkan peserta untuk berpartisipasi dalam pembelajaran online mandiri, (c) kurangnya pengetahuan masyarakat tentang penggunaan teknologi, (d) properti siswa yang tidak konsisten seperti komputer dan akses internet.

\section{Pendidikan Geografi}

Hakikat geografi sebagai ilmu selalu mempertimbangkan semua fenomena di ruang semesta, dengan memperhatikan secara khusus setiap aspek yang merupakan bagian dari keseluruhan, faktor alam dan faktor manusia yang membentuk keterpaduan spasial di wilayah yang ditinjau. Interaksi dan integrasi spasial merupakan inti dari kerangka dasar geografi dan geografi. Geografi adalah ilmu yang mempelajari gejala dan sifat permukaan bumi dan penghuninya, diklasifikasikan menurut lokasinya, dan berusaha menjelaskan interaksi antara gejala dan sifat tersebut.

Studi geografi adalah studi tentang hakikat geografi, yang diajarkan di sekolah dan disesuaikan dengan tingkat perkembangan intelektual anak pada setiap jenjang pendidikan. Berdasarkan Permendikna Nomor 22 Tahun 2006 tentang Standar Isi (SI), pembelajaran geografi membantu siswa memahami variasi dan organisasi spasial orang, tempat, dan lingkungan di permukaan bumi, serta mendorong siswa untuk memahami aspek fisik dan proses yang mengatur pola tersebut, permukaan bumi, sifat spasial ekologi dan sebarannya di permukaan bumi. Selain itu, siswa termotivasi secara aktif dan kreatif untuk mengeksplorasi dampak budaya dan pengalaman pada persepsi manusia tentang tempat dan wilayah. Pengetahuan, keterampilan, dan nilai-nilai yang diperoleh dalam studi geografi dimaksudkan untuk memperkuat kemampuan peserta didik untuk berperilaku bijaksana, wajar, dan bertanggung jawab dalam menghadapi masalah sosial, ekonomi, dan lingkungan.

\section{Blended Learning Pendidikan Geografi pada Sekolah Menengah Atas}

Di masa pandemi COVID 19 saat ini, menggunakan pembelajaran dengan blended learning menjadi suatu alternatif yang paling baik (Widyasari \& Rafsanjani, 2021). Hal ini disebabkan semakin minimnya waktu untuk bertatap muka di dalam kelas dan melakukan pembelajaran seperti pada umumnya, maka pengunaan teknologi digital menjadi satu-satunya pilihan agar proses pembelajaran tetap berlangsung. Dalam hal ini akan menyajikan deskripsi probelamtika dan implementasi Pelajaran Geografi selama pandemi di SMAN Darussholah Singojuruh, Banyuwangi menggunakan metode blended learning.

Aktivitas Learning From Home (LFH) ini menjadi tantangan tersendiri bagi guru dan siswa. dan orang tua, karena mereka belum pernah mengalaminya sebelumnya. Kolaborasi antara guru dan orang tua menjadi kunci utama keberhasilannya (Abroto et al., 2021). Para peneliti percaya bahwa kerjasama yang baik ini pasti akan berdampak baik pada semua aspek, termasuk studi geografi. Problematika PJJ tidak hanya dialami oleh satu pihak, melainkan dirasakan juga oleh guru, siswa, dan orang tua (Septiani \& Putra, 2020).

Problematika dari pihak Guru :

1. Guru dituntut dapat bisa beradaptasi dengan model pembelajaran bermodel blended learning pada masa pandemi saat ini. Penggunaan perangkat IT sedikit demi sedit guru harus bisa menguasai dalam pemberian pembelajaran selama online,

2. Guru harusnya membuat kurikulum yang terbaru sehingga pembelajaran dapat menyesuaikan keadaan dalam sistem pembelajaraan online.

3. Guru juga dituntut untuk kreatif dalam pemberian materi supaya siswa tidak mengalami kebosanan saat proses pembelajaran melalui google meet. Guru harus bisa memvariasi platfrom sehingga siswa tidak monoton dalam proses pembelajaran.

4. Kegiataan ini mengakibatkan kedetakan guru dengan siswa memiliki jarak, sehingga guru juga tidak bisa membimbing secara lansung kepada siswa yang mengakibatkan siswa banyak yang belum menguasi materi saat melakukan Google meet. 
5097 Blended Learning dan Implikasinya terhadap Hasil Belajar Geografi Siswa SMA di Era Pandemi Covid-19 - Lesmiyati Hariyani

DOI: https://doi.org/10.31004/edukatif.v3i6.1643

\section{Problematika dari sisi siswa}

1. Perubahan lingkungan belajar akan mempengaruhi masalah psikologis siswa. Permasalahan yang dihadapi siswa berupa stigma bahwa kegiatan belajar (sekolah) harus berlangsung di lembaga pendidikan, jika di rumah berarti sedang berlibur. Mengubah kebiasaan dan cara pandang anak tentang sekolah menjadi masalah yang cukup menegangkan bagi orang tua, apalagi jika anak tidak terbiasa dengan sekolah reguler di rumah. Selain itu, anak sering enggan belajar dengan orang tuanya karena orang tua belum tentu memiliki keterampilan yang sama dengan guru di sekolah.

2. Kesehatan mata peserta didik bisa terganggu lantaran siswa "dipaksa" untuk berada di depan layar HP, laptop, ataupun perangkat lainnya karena sistem pembelajaran yang diubah dari tatap muka langsung menjadi tatap muka virtual (melalui Google Meet ) dari pukuln 07.30-11.30.

3. Kejenuhan siswa. Siswa jenuh karena rutinitas tiap hari menjdi berubah. Setiap hari siswa harus belajar di depan layar monitor atau HP, mengerjakan tugas mandiri, tidak ada interaksi dengan teman dan guru

Probelamtika dari sisi orang tua

1. Orang tua sebagai aktor sentral dalam home education juga tidak luput dari berbagai permasalahan. Ketika siswa belajar dari rumah, orang tua memiliki, selain pekerjaan utama mereka sebagai juru tulis, pedagang, tenaga kesehatan, dll. Tidak semua orang tua dapat meluangkan waktu untuk menemani anakanak mereka belajar dan tugas-tugas lainnya (Kutsiyyah, 2021).

2. Tidak semua orang tua memiliki keterampilan menggunakan IT dan perangkat kerja berbasis internet, hal ini juga menjadi tantangan dan membutuhkan waktu untuk beradaptasi. Namun, sebagian besar orang tua sudah mengenal baik perangkat elektronik (tablet, laptop/komputer dan smartphone) dan aktif menggunakan berbagai media sosial seperti Facebook, YouTube dan Line. Oleh karena itu, hanya sebagian kecil saja yang akan menemui kendala dan membutuhkan dukungan dalam memenuhi perannya sebagai pendamping anak dalam pembelajaran di rumah.

3. Sistem pembelajaran yang megharuskan siwa menggunakan perangkat elektronik seperti smarphone, tablet, laptop atau komputer, mengahuaruskan orang tua untuk memberikan fasilitas tersebut. Hal yang menjadi kendala, jika di rumah ada lebih dari satu anak yang sekolah daring, maka perangkat IT yang digunakan juga harus disesuaikan.

4. Terkait masalah keuangan, orang tua harus mengalokasikan dananya untuk penggunaan wifi, kuota internet untuk mendukung proses pembelajaran siswa selama belajar daring

Penggunaan blended learning dalam pelajaran geografi di pendidikan menengah akan melengkapi model pembelajaran yang sebelumnya hanya digunakan dalam pengajaran tatap muka. Kegiatan diharapkan lebih interaktif antara guru dan siswa, serta dengan sesama siswa. Blended learning merupakan sarana pembelajaran bagi siswa yang kebutuhan belajarnya masih di bawah rata-rata. Blended learning mampu menarik perhatian siswa karena caranya membuat pembelajaran menjadi lebih menarik (Purnama, 2020).

Pelaksanaan pembelajaran dapat dirancang melalui kombinasi media pembelajaran, karena gaya belajar setiap siswa berbeda. Kita sebagai pendidik atau orang tua tidak dapat memaksa siswa untuk belajar dalam suasana dan cara yang kita inginkan, karena setiap siswa atau individu memiliki tipe atau gaya belajarnya masing-masing. Salah satu cara yang dapat dicapai blended learning adalah kombinasi pembelajaran jarak jauh dan penggunaan multimedia interaktif atau media audiovisual untuk mencapai pembelajaran offline (Dwiyogo, 2018).

Pengembangan langkah-langkah pembelajaran dalam blended learning. Dalam mengembangkan pembelajaran baik melalui penerapan blended learning maupun secara konvensional, pendidik perlu menyusun langkah-langkah pembelajaran yang tepat dalam suatu rencana pelaksanaan pembelajaran (RPP) berdasarkan kompetensi tersebut. Pengembangan langkah-langkah pembelajaran yang menggunakan blended learning juga harus dirancang dengan baik agar siswa tidak mengalami kesulitan teknis dalam melaksanakan pembelajaran. Oleh karena itu, pendidik perlu mempersiapkan terlebih dahulu segala sesuatu yang diperlukan, 
5098 Blended Learning dan Implikasinya terhadap Hasil Belajar Geografi Siswa SMA di Era Pandemi Covid-19 - Lesmiyati Hariyani

DOI: https://doi.org/10.31004/edukatif.v3i6.1643

materi yang akan disampaikan atau dibahas, platform yang akan digunakan dalam pembelajaran dengan blended learning, tutorial dan tutorial cara menggunakan pembelajaran dembunan.

Dengan manajemen yang baik, sistem pembelajaran ini bisa berjalan sesuai harapan sebagaimana negara-negara maju. Sebaliknya jika tidak dengan persiapan yang matang, akan lebih banyak kerugian yang didapat dari pada nilai positif dari pembelajaran daring sebagimana dijelaskan Coman dkk. dalam penelitiannya di lembaga pendidikan tinggi Rumania sehingga pembelajaran daring. Namun dalam kondisi nyata di lapangan, terdapat beberapa kendala yang sangat signifikan dan mendasar dalam pembelajaran daring ini selama pandemi. Sebagaimana sering kali didapati peserta didik banyak siswa yang tidak aktif selama proses pembelajaran seperti kurang menyampaikan aspirasi dan pendapatnya sehingga yang dirasakan pembelajaran tersebut menjenuhkan dan tidak "hidup" sebagaimana tatap muka. Fakta ini juga selaras dengan penelitian yang dilakukan oleh (Kutsiyyah, 2021)yang menyebutkan bahwa pembelajaran daring siswa cenderung tidak berperan aktif dalam pembelajaran, sehingga pembelajaran terasa membosankan dan menurunkan semangat dan minat belajar siswa.

Fakta di atas menggambarkan bahwa pembelajaran daring tidak bisa secara penuh memenuhi kebutuhan dalam pendidikan. Ada banyak pengalaman yang bisa diambil dari pembelajaran tatap muka. Maka beberapa lembaga pendidikan juga mengambil model campuran untuk mendapat lebih banyak pengalaman dalam belajar. Blended learning represents a combination of face-to-face experiences and online learning experiences. Pengalaman dari pembelajaran daring dan tatap muka akan membantu menawarkan kesempatan untuk mencapai tujuan pendidikan lebih lanjut.

Blended learning atau pembelajaran gabungan merupakan konsep pembelajaran yang menggabungkan antara pembelajaran online/daring dengan tatap muka. Model ini dapat dijadikan alternatif dan menjawab persoalan pembelajaran daring secara penuh (e-learning) yang tidak bisa menjangkau semua daerah dan beberapa aspek pendidikan yang tidak bisa disampaikan hanya dengan daring (Handoko \& Waskito, 2018). Selain Blended learning bisa menjadi jawaban dari kelemahan yang ada pada pembelajaran online, juga mampu menjadi solusi bagi pembelajaran tatap muka yang selalu terikat tempat dan waktu sehingga bisa menjadi lebih fleksibel dan menjangkau luas pengalaman belajar. Di sisi lain, ada hal signifikan dalam dunia pendidikan yang juga tidak bisa disampaikan secara daring, seperti nilai-nilai moral yang butuh role model dan juga praktikum yang butuh bimbingan, fasilitas dan kerja nyata.

\section{KESIMPULAN}

Dari berbagai sumber literatur dan penelitian, ditemukan bahwa pembelajaran online adalah kebiasaan baru dalam dunia pendidikan di masa pandemi covid-19. Blended learning merupakan salah satu metode pembelajaran yang dapat digunakan dalam pembelajaran online saat ini. Hal ini dikarenakan kemudahan dan kepraktisan dalam melaksanakan proses pembelajaran yang dapat dilakukan secara mandiri melalui pemanfaatan media digital seperti internet, media sosial dan sejenisnya. Media yang sudah sangat familiar di masyarakat menjadi pilihan populer yang dapat membantu proses pembelajaran terutama di masa pandemi. Fleksibilitas pembelajaran online bukan tanpa masalah. Karena berbasis internet dan membutuhkan kemandirian dalam belajar, maka terdapat pula problematika yang dihadapi oleh pelaku pendidikan seperti kuota internet, jaringan yang sulit diakses, keterampilan tenaga pengajar dan wali murid, serta kurangnya motivasi siswa dalam mencapai hasil yang maksimal. Mengingat hambatan yang banyak dirasakan siswa, guru dan orang tua, namun juga tidak memungkiri manfaat dan kelebihan pembelajaran online, blended learning merupakan salah satu solusinya. Hal ini juga dapat menjadi peluang bagi penelitian selanjutnya untuk mengkaji lebih dekat blended learning sebagai harapan baru dalam pendidikan di masa depan.

\section{DAFTAR PUSTAKA}

Abroto, A., Maemonah, M., \& Ayu, N. P. (2021). Pengaruh Metode Blended Learning Dalam Meningkatkan 
5099 Blended Learning dan Implikasinya terhadap Hasil Belajar Geografi Siswa SMA di Era Pandemi Covid-19 - Lesmiyati Hariyani

DOI: https://doi.org/10.31004/edukatif.v3i6.1643

Motivasi dan Hasil Belajar Siswa Sekolah Dasar. Edukatif: Jurnal Ilmu Pendidikan, 3(5), 1993-2000.

Ceylan, V. K., \& Kesici, A. E. (2017). Effect of Blended Learning to Academic Achievement. Journal of Human Sciences, 14(1), 308. https://doi.org/10.14687/jhs.v14i1.4141

Dihamri, Haimah, Sugandi, W., Zairin, \& Srifitriani, A. (2021). Blended Learning Alternatif Pembelajaran Pada Pendidikan Tinggi Era New Normal Melalui Pembelajaran Daring. Jurnal Georafflesia, 6(1), 110.

Dwiyogo, W. D. (2018). Developing a Blended Learning-Based Method for Problem-Solving in Capability Learning. TOJET:The Turkish Online Journal of Educational Technology, 17(1), 51-61.

Dziuban, C., \& Moskal, P. (2011). A Course is a Course is a Course: Factor Invariance in Student Evaluation of Online, Blended and Face-to-face Learning Environments. Internet and Higher Education, 14(4), 236-241. https://doi.org/10.1016/j.iheduc.2011.05.003

Handoko, H., \& Waskito, W. (2018). Blended Learning: Konsep dan Penerapannya. In Blended Learning: Konsep dan Penerapannya. Jurnal Pendidikan.

Jamaluddin, D., Ratnasih, T., Gunawan, H., \& Paujiah, E. (2020). Pembelajaran Daring Masa Pandemik Covid-19 Pada Calon Guru: Hambatan, Solusi dan Proyeksi. In Karya Tulis Ilmiah UIN Sunan Gunung Djjati Bandung. Bandung.

Kutsiyyah. (2021). Analisis Fenomena Pembelajaran Daring Pada Masa Pandemi (Harapan Menuju Blended Learning). Edukatif: Jurnal Ilmu Pendidikan, 3(4), 1460-1469.

Masgumelar, N. K., \& Mustafa, P. S. (2021). Pembelajaran Pendidikan Olahraga Berbasis Blended Learning Untuk Sekolah Menengah Atas. Jurnal Kejaora (Kesehatan Jasmani Dan Olah Raga), 6(1), 133-144. https://doi.org/10.36526/kejaora.v6i1.1222

Masykuri, N. M. (2020). Inovasi Blended Learning Pada Pembelajaran Pendidikan. Seminar Nasional Keolahragaan, 1-5. Malang.

Medina, L. C. (2017). Blended learning: Deficits and Prospects in Higher Education. Australasian Journal of Educational Technology, 34(1), 42-56.

Nande, M., \& Irman, W. A. (2021). Penerapan Model Pembelajaran Blended Learning dalam Meningkatkan Hasil Belajar Siswa Sekolah Menengah Kejuruan. Edukatif: Jurnal Ilmu Pendidikan, 3(1), 180-187. https://doi.org/10.31004/edukatif.v3i1.240

Nurhadi, N. (2020). Blended Learning dan Aplikasinya di Era New Normal Pandemi Covid-19. Agriekstensia, $19(2), 121-128$.

Purnama, M. N. A. (2020). Blended Learning Sebagai Sarana Optimalisasi Pembelajaran Daring di Era New Normal. SCAFFOLDING: Jurnal Pendidikan Islam Dan Multikulturalisme, 2(2), 106-121. https://doi.org/10.37680/scaffolding.v2i02.535

Septiani, M., \& Putra, D. D. (2020). Penerapan Blended Learning Pada Mata Kuliah Dasar-dasar Pengembangan Kurikulum. Educate, 5(1), 86-109. https://doi.org/10.32832/educate.v5i1.2020

Sugiyono. (2017). Metode Penelitian Bisnis (Pendekatan Kuantitatif, Kualitatif dan R\&D). Bandung: Alfabeta.

Susanti, D. I., \& Prameswari, J. Y. (2020). Adaptasi Blended Learning di Masa Pandemi COVID-19 untuk Pembelajaran Bahasa Inggris di Sekolah Dasar. Lingua Susastra, 1(2), 50-61. https://doi.org/10.24036/ls.v1i2.8

Utari, W., Hikmawati, V. Y., \& Gaffar, A. A. (2020). Blended Learning: Strategi Pembelajaran Alternatif Di Era New Normal. Seminar Nasional Pendidikan, FKIP UNMA 2020 "Transformasi Pendidikan Sebagai Upaya Mewujudkan Sustainable Development Goals (SDCs) Di Era Society 5.0,”262-269.

Widyasari, L. A., \& Rafsanjani, M. A. (2021). Apakah Penerapan Blended Learning Dapat Meningkatkan Motivasi dan Hasil Belajar Siswa dalam Pembelajaran Jarak Jauh? Edukatif: Jurnal Ilmu Pendidikan, 
5100 Blended Learning dan Implikasinya terhadap Hasil Belajar Geografi Siswa SMA di Era Pandemi Covid-19 - Lesmiyati Hariyani

DOI: https://doi.org/10.31004/edukatif.v3i6.1643

3(3), 854-864.

Yudiawan, A. (2020). Belajar Bersama COVID 19: Evaluasi Pembelajaran Daring Era Pandemi di Perguruan Tinggi Keagamaan Islam Negeri, Papua Barat. AL-FIKR: Jurnal Pendidikan Islam, 6(1), 10-16.

https://doi.org/10.32489/alfikr.v6i1.64 